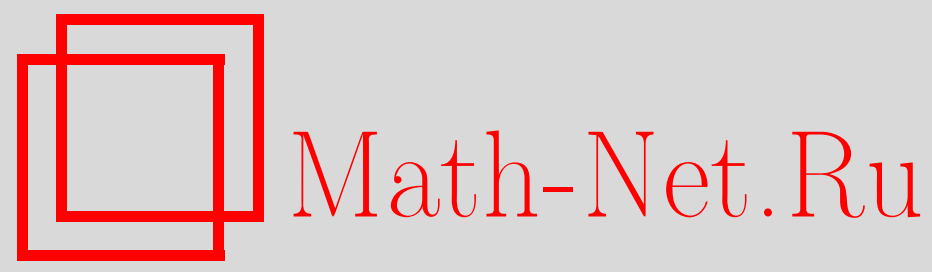

В. А. Воблый, Асимптотика числа бесповторных булевых функций в базисе $B_{1}$, Дискрет. матем., 2010, том 22, выпуск 4, 156-157

DOI: https://doi.org/10.4213/dm1125

Использование Общероссийского математического портала Math-Net.Ru подразумевает, что вы прочитали и согласны с пользовательским соглашением http://www . mathnet.ru/rus/agreement

Параметры загрузки:

IP : 3.89 .185 .249

26 апреля 2023 г., 05:46:55 
УДК 519.6

\title{
Асимптотика числа бесповторных булевых функций в базисе $B_{1}$
}

\author{
() 2010 г. В. А. Воблый
}

Для числа $S_{n}$ бесповторных булевых функций от $n$ переменных в базисе $B_{1}$ доказано, что при $n \rightarrow \infty$

$$
S_{n} \sim c n^{-3 / 2} \alpha^{n} n !,
$$

где $c$ и $\alpha$ - константы.

Пусть $S_{n}$ - число бесповторных булевых функций от $n$ переменных в базисе $B_{1}$. В [1] получено рекуррентное соотношение

$$
S_{n}=3 S_{n-1}+\sum_{i=1}^{n-1}\left(\begin{array}{l}
i-1 \\
n-1
\end{array}\right)\left(S_{i}+S_{i-1}+\sum_{j=1}^{i-1}\left(\begin{array}{c}
i-1 \\
j-1
\end{array}\right) S_{j} S_{i-j}\right) S_{n-i} .
$$

Теорема 1. При $n \rightarrow \infty$

$$
S_{n} \sim c n^{-3 / 2} \alpha^{n} n !, \quad \alpha=(\ln (1+\sqrt{5} / 2)+(1-\sqrt{5}) / 2)^{-1}=7,5498 \ldots
$$

Доказательство. Введем производящую функцию

$$
S(x)=\sum_{n=1}^{\infty} S_{n}\left(x^{n} / n !\right)
$$

Разностное уравнение для $S_{n}$ равносильно следующему уравнению для $S(x)$ :

$$
x\left(S^{\prime}(x)-2\right)=3 x S(x)+x S^{\prime}(x) S(x)+x S^{2}(x)+x S^{\prime}(x) S^{2}(x) .
$$

Решая это дифференциальное уравнение с разделяющимися переменными, находим, что

$$
x=\ln (1+S(x))+\ln (1+S(x) / 2)-S(x) .
$$

Разлагая логарифм в окрестности точки 0, получаем сходящийся ряд

$$
x=\frac{1}{2} S-\frac{5}{8} S^{2}+\ldots
$$

Обращая этот ряд с помощью формулы обращения Лагранжа (см. с. 419 в [2]), получаем, что

$$
\frac{S_{n}}{n !}=\frac{1}{2 \pi i n} \oint \frac{d z}{(\ln (1+z)+\ln (1+z / 2)-z)^{n}} .
$$


Применим теперь метод перевала для получения асимптотики $S_{b}$ при $n \rightarrow \infty$. Пусть

$$
I(n)=\frac{1}{2 \pi i} \oint e^{n f(z)} d z, \quad f(z)=\ln (\ln (1+z)+\ln (1+z / 2)-z),
$$

тогда

$$
S_{n}=(n-1) ! I(n) .
$$

Так как $f^{\prime}(z)=0$ при $z^{2}+z+1=0$, существуют две точки перевала $z=-(1+\sqrt{5}) / 2$ и $z=-(\sqrt{5}-1) / 2$. Поскольку $f^{\prime \prime}\left(z_{1}\right) \neq 0$ и $f^{\prime \prime}\left(z_{2}\right) \neq 0$, обе точки являются простыми точками перевала, и асимптотика интеграла $I(n)$ при $n \rightarrow \infty$ дается формулой (см. с. 480 в [2])

$$
I(n) \sim \frac{c}{\sqrt{n}}\left(e^{n f\left(z_{1}\right)}+e^{n f\left(z_{2}\right)}\right) .
$$

Вычисляя значения $e^{f(z)}$ в точках перевала, находим, что

$$
\begin{aligned}
& \alpha=e^{f\left(z_{2}\right)} \sim 7,5, \\
& \beta=e^{f\left(z_{1}\right)} \sim 0,31,
\end{aligned}
$$

таким образом, вклад в асимптотику первой точки перевала экспоненциально мал по сравнению с вкладом второй точки перевала.

Теорема доказана.

Автор благодарит В. К. Леонтьева за постановку задачи.

\section{Список литературы}

1. Винокуров С. Ф., Перязев Н. А., Избранные вопросы теории булевых функичй. Физматлит, Москва, 2001.

2. Лаврентьев М. А., Шабат Б. М., Методы теории функций комплексного переменного. Наука, Москва, 1965.

Статья поступила 18.11.2009. 